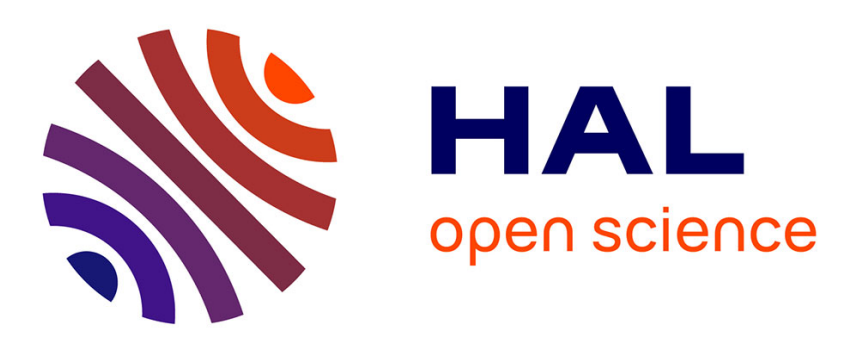

\title{
Structural parameters that determine the rheological properties of apple puree
}

Lucia Brisset Espinosa-Muñoz, Catherine Renard, Ronan Symoneaux, N. Biau, Gerard Cuvelier

\section{To cite this version:}

Lucia Brisset Espinosa-Muñoz, Catherine Renard, Ronan Symoneaux, N. Biau, Gerard Cuvelier. Structural parameters that determine the rheological properties of apple puree. Journal of Food Engineering, 2013, 119 (3), pp.619-626. 10.1016/j.jfoodeng.2013.06.014 hal-01001549

\section{HAL Id: hal-01001549 \\ https://hal.science/hal-01001549}

Submitted on 29 May 2020

HAL is a multi-disciplinary open access archive for the deposit and dissemination of scientific research documents, whether they are published or not. The documents may come from teaching and research institutions in France or abroad, or from public or private research centers.
L'archive ouverte pluridisciplinaire HAL, est destinée au dépôt et à la diffusion de documents scientifiques de niveau recherche, publiés ou non, émanant des établissements d'enseignement et de recherche français ou étrangers, des laboratoires publics ou privés. 


\title{
Structural parameters that determine the rheological properties of apple puree
}

\author{
L. Espinosa-Muñoz ${ }^{\text {a,b,* }}$, C.M.G.C. Renard ${ }^{c}$, R. Symoneaux ${ }^{\text {d }}$, N. Biau ${ }^{\text {e }}$, G. Cuvelier $^{\text {a,b }}$ \\ a AgroParisTech, UMR1145 Ingénierie Procédés Aliments, 91300 Massy, France \\ b INRA, UMR1145 Ingénierie Procédés Aliments, 91300 Massy, France \\ ' INRA, UMR408 Sécurité et Qualité des Produits d'Origine Végétale, Université d'Avignon et des Pays du Vaucluse, 84000 Avignon, France \\ ${ }^{\mathrm{d}}$ LUNAM, GROUPE ESA, UPSP GRAPPE, 55 Rue Rabelais, 49007 Angers, France \\ ${ }^{\text {e } C o n s e r v e s ~ F r a n c e, ~ D o m a i n e ~ d u ~ G r a n d ~ F r i g o l e t, ~} 13150$ Tarascon, France
}

Keywords:

Structure

Mechanical treatment

Rheology

Plant food dispersions

\begin{abstract}
A B S T R A C T
The objective of this work is to better understand how the structural parameters (particle content, particle size and serum viscosity) influence the rheological properties of apple purees. An apple puree (called "native") was ground to obtain dispersions with three different particle size distributions. This mechanical treatment induced the separation of parenchyma irregular cell clusters into regular single cells, modifying both the morphology and the particle size distribution of purees. A separation-reconstitution step made it possible to obtain samples with a wide range of insoluble solids $(8-24 \mathrm{~g} / \mathrm{kg}$ ). Pectin was added to some of the samples in order to increase the viscosity of the continuous phase. The rheological behaviour and structural properties of the modified apple purees were investigated using flow and oscillatory rheological measurements, particle size measurements and confocal laser scanning microscopy. Rheological properties such as apparent viscosity, yield stress and elastic modulus decreased as particle size decreased and they increased as insoluble solids content increased. Modelling of rheological properties with master curves made it possible to take into account the apparent relative volume occupied by the particles of different sizes.
\end{abstract}

\section{Introduction}

In recent years there has been a great interest in consuming foods containing dietary fibre, due to its great potential for beneficial effects in health and well being. Plant-based foods are one of the most important platforms because the plant cell walls, which are their major structural component and can be present in high concentrations, are dietary fibres (Redgwell and Fischer, 2005; Sun-Waterhouse, 2010).

During processing, plant cell walls undergo modifications in terms of their physical state, macrostructure, microstructure, and composition, as well as structure-dependent changes in their functional and material properties. Fruit purees are obtained after a thermal (cooking) and mechanical (grinding) treatment of the fruits. These treatments will considerably influence the structure and the material properties of the system (Kunzek et al., 1999).

From a physical point of view, fruit purees can be considered as concentrated dispersions of soft and deformable insoluble particles

* Corresponding author at: AgroParisTech, UMR1145 Ingénierie Procédés Aliments, 91300 Massy, France. Tel.: +33 642561815.

E-mail addresses: lucy.espinosa@gmail.com, lucia.brisset@agroparistech.fr (L. Espinosa-Muñoz). that are dispersed into an aqueous solution of sugars, organic acids and pectic substances called the serum (Cepeda and Gomez, 2002; Rao, 1999). The solid insoluble particles in plant food dispersions are of various shapes and have multimodal size distributions. They are constituted of cell wall "ghosts" of cells and their aggregates from parenchyma tissue. Their constitutive units are thus the cell walls of the corresponding fruit. The parenchyma tissue of the apple contains cells with irregular shapes and diameters between 50 and $200 \mu \mathrm{m}$, which are connected by the pectin of the middle lamella (Khan and Vincent, 1993; Kunzek et al., 1999).

Rheological parameters can provide analytical tools to yield meaningful insight on the structural organisation of food (Ahmed and Ramaswamy, 2007). Fruit purees behave as non-Newtonian fluids: in general, purees of fruits and vegetables are shear thinning fluids (Rao, 1992) presenting a yield stress. Plant food dispersions have usually been described by a power law model and also by different models that include the yield stress as a fitting parameter, such as the Herschel-Bulkley and Casson models (Colin-Henrion et al., 2009; Qiu and Rao, 1988). The properties of different plant food dispersions depend on the raw material and are influenced not only by the concentration but also by the particle size, stiffness, composition, and elastic properties (Day et al., 2010; Den Ouden and Van Vliet, 2002; Kunzek et al., 1999, 1997; Maceiras et al., 
Version définitive du manuscrit publiée dans / Final version of the manuscript published in :

Journal of Food Engineering (2013), Vol. 119, $\mathbf{N}^{\circ} .3$, p. 619-626, DOI: 10.1016/j.jfoodeng.2013.06.014

Journal homepage: http://www.elsevier.com/locate/ifoodeng

2007; Nindo et al., 2007). The rheological properties are expected to depend on both the soluble solids in the serum phase and the particle volume fraction of insoluble solids (Lopez-Sanchez et al., 2011; Rao, 1992; Vitali and Rao, 1982), contributing to the complex rheological behaviour of the plant food dispersions. The volume fraction occupied by the cell wall particles in suspension remains difficult to estimate as it depends on the arrangement of the soft particles, which in turn is determined by the particle shape, stiffness and size distribution (Cepeda and Gomez, 2002; Hemar et al., 2011). Recently, Day et al. (2010) have attempted an estimate of the volume fraction of particles in dispersions of carrot and broccoli using dynamic oscillatory measurements, in our knowledge no information is available on the volume fraction of apple puree.

In our previous work (Espinosa-Muñoz et al., 2012) we studied the effect and the importance of the structural parameters (particle size, solids content and serum rheology) for the sensory perception of apple puree's texture. We now study and evaluate the influence of these structural parameters on the rheological behaviour of apple purees. A mechanical treatment was used to modulate the particles size and shape, separation/reconstitution to modulate solids content, and addition of pectin to modify serum viscosity. Structural parameters of apple purees were thus modified in a controlled manner to investigate their impact on the dynamic and steady-flow rheological characteristics. Microscopy techniques were also used to characterise the structure of the apple purees.

\section{Material and methods}

\subsection{Plant material and processing conditions}

A single batch of fresh mature apple Golden Delicious was industrially processed into puree by Conserves France according to industrial best practices. Apple pieces were refined (sieve opening of $1.2 \mathrm{~mm}$ ) and cooked $\left(98^{\circ} \mathrm{C}, 4 \mathrm{~min}\right)$. Finally purees were conditioned in hermetically sealed bags. This sample is called Native Puree (NP).

\subsection{Preparation of apple purees varying particle size and solids content}

In order to vary the particle size and to study the impact of mechanical treatment, NP was ground in a Grindomix GM 200 (Retsch GmbH, Germany) at $5000 \mathrm{rpm}$ for $15 \mathrm{~s}$, sample denoted as MG (Medium Ground), and at 10,000 rpm for $3 \mathrm{~min}$, sample called HG (Highly Ground).

To obtain samples with a wide range of solids content, the pulp and the serum from NP, MG and HG purees were separated by centrifugation at $5000 \mathrm{~g}$ for $2 \mathrm{~h}$ at $20^{\circ} \mathrm{C}$ in a $3.18 \mathrm{~K}$ centrifuge (Sigma $\mathrm{GmbH}$, Germany). After the separation, samples with varying cell wall content were prepared by weighing and mixing the pulp and serum in different ratios (Table 1).

To modify the viscosity of the serum, $1 \%$ of amidated pectin (Herbstreith \& Fox KG: Pectin Amid CF 005-D E440) was dispersed directly in purees, mixed at ambient temperature with a pale flat stirrer (Bioblock, Scientific) for $15 \mathrm{~min}$ at $200 \mathrm{rpm}$. A test was carried out using the rheometer MCR-301 (Anton Paar, Physica) to verify complete dissolution of pectin.

\subsection{Dry insoluble solids content (ISC)}

Apple purees were separated by centrifugation as described in Section 2.2. The insoluble material was then prepared from the pulp as alcohol insoluble solids (Renard, 2005) with a supplementary first "washing" step. This step consisted of a centrifugation after the addition of a buffer solution $(50 \mathrm{mM}$ sodium acetate,
Table 1

Sample coding and processing conditions.

\begin{tabular}{lcll}
\hline Sample & $\begin{array}{l}\text { Solids concentration } \\
\text { (g dry insoluble solids/kg } \\
\text { puree) }\end{array}$ & Grinding & $\begin{array}{l}\text { Pectin added }(\mathrm{g} / \\
100 \mathrm{~g})\end{array}$ \\
\hline NP8 & 8 & - & 0 \\
NP & 11 & - & 0 \\
NP16 & 16 & - & 0 \\
NP21 & 21 & - & 0 \\
MG7 & 7 & $5000 \mathrm{rpm} / 15 \mathrm{~s}$ & 0 \\
MG & 11 & $5000 \mathrm{rpm} / 15 \mathrm{~s}$ & 0 \\
MG18 & 18 & $5000 \mathrm{rpm} / 15 \mathrm{~s}$ & 0 \\
MG20 & 20 & $5000 \mathrm{rpm} / 15 \mathrm{~s}$ & 0 \\
HG & 11 & $10,000 \mathrm{rpm} /$ & 0 \\
& & $3 \mathrm{~min}$ & \\
HG16 & 16 & $10,000 \mathrm{rpm} /$ & 0 \\
& & $3 \mathrm{~min}$ & \\
HG24 & 24 & $10,000 \mathrm{rpm} /$ & 0 \\
NP8 + P & 8 & $3 \mathrm{~min}$ & \\
NP16 + P & 16 & - & 1 \\
HG + P & 11 & - & 1 \\
HG16 + P & 16 & $10,000 \mathrm{rpm} /$ & 1 \\
& & $3 \mathrm{~min}$ & \\
& & $10,000 \mathrm{rpm} /$ & 1 \\
& & $3 \mathrm{~min}$ & \\
\hline
\end{tabular}

adjusted to $\mathrm{pH} 3.5$ with acetic acid) to the pulp to eliminate the soluble pectin trapped by the particles in the serum. Approximately $5 \mathrm{~g}$ of pulp were suspended in the buffer solution (15 $\mathrm{mL})$, mixed in a vortex and centrifuged $\left(13,200 \mathrm{~g}, 12 \mathrm{~min}, 10^{\circ} \mathrm{C}\right)$. The sediment was washed again with the buffer solution, two washes were judged to be significant (elimination of approximately 15 sixteenth of the serum) while leading to an acceptable risk of pectin extraction from the cell walls. The second sediment was blended with $96 \%$ ethanol (1:3), and stirred at $4{ }^{\circ} \mathrm{C}$ over $12 \mathrm{~h}$. The next steps followed the procedure described in Renard (2005) which included washing by $70 \%$ ethanol and then drying by solvent exchange. Insoluble solids content was expressed as the relation between the dry materials weight and the initial sample weight.

\subsection{Pulp content}

The pulp content of the samples was determined in triplicate by centrifugation at $5000 \mathrm{~g}$ for $2 \mathrm{~h}$ at $20^{\circ} \mathrm{C}$. The pulp content was expressed as the relation between the pulp weight $\left(W_{p}\right)$ and the initial sample weight $\left(W_{s}\right)$ (Qiu and Rao, 1988).

Pulp $\%=\frac{W_{p}}{W_{s}} \times 100$

\subsection{Particle size distribution}

The particle size distribution (PSD) of the samples was measured using a laser diffraction analyser (Master Sizer, Malvern Instruments Ltd., UK), applying the Fraunhofer optical model. The $d(0.9)$ represents the diameter above which there is only $10 \%$ (in volume) of bigger particles. Analysis was done on the diluted samples in distilled water; each sample was run in triplicate.

\subsection{Confocal scanning laser microscopy}

Confocal laser scanning microscopy was used to visualise the dispersed particles by colouring the cell wall material. Samples were diluted 15 times with serum obtained previously by centrifugation (part 2.2) and they were stained with 5 drops of the fluorescent dye congo red ( $10 \mathrm{~g} / \mathrm{L}$ in water, Sigma Aldrich) at $20^{\circ} \mathrm{C}$ for $3 \mathrm{~h}$. 
Version définitive du manuscrit publiée dans / Final version of the manuscript published in :

Journal of Food Engineering (2013), Vol. 119, N.3, p. 619-626, DOI: 10.1016/j.jfoodeng.2013.06.014

Journal homepage: http://www.elsevier.com/locate/jfoodeng

The stained samples were placed on glass slides with a $1 \mathrm{~mm}$ shim and finally covered with the cover slips. Imaging was performed using a Leica TCS SP5 confocal laser scanning microscope (Leica Microsystems, Wetzlar, Germany) using a $10 \times$ objective lens. Red congo dye was excited by an argon $488 \mathrm{~nm}$ laser and the emitted light was collected in the range of 529-689 nm.

\subsection{Rheological measurements}

Rheological measurements were carried out using an MCR-301 controlled stress rheometer (Anton Paar, Germany) at $20^{\circ} \mathrm{C}$ in triplicate.

\subsubsection{Steady state measurements}

Steady state measurements of apple purees used a concentric cylinder geometry consisting of a rotating rough inner cylinder with a radius of 9.46 and $40 \mathrm{~mm}$ immersed height, and the outer stationary cup with a radius of 14.46 , thus giving a gap of 5.0 $\mathrm{mm}$. A pre-shear rate of $43 \mathrm{~s}^{-1}$ was applied to the puree for $1 \mathrm{~min}$, and the apparent viscosity was obtained from this step. Then the shear rate was increased from 2.14 to $214 \mathrm{~s}^{-1}$ for $5 \mathrm{~min}$ and decreased from 214 to $2.14 \mathrm{~s}^{-1}$ for $5 \mathrm{~min}$. Flow properties were described by the Herschel-Bulkley model.

\subsubsection{Oscillatory measurements}

Oscillatory tests of apple purees were carried out using a six blade vane geometry, with an inner radius of $11 \mathrm{~mm}$ and a height of $16 \mathrm{~mm}$. The outer stationary cup had an outer radius of 14.46 giving a gap of $3.46 \mathrm{~mm}$.

Oscillatory strain sweep tests were performed at an angular frequency of $10 \mathrm{rad} / \mathrm{s}$ in order to determine the range of linear viscoelastic response (LVER) or the limit of linearity where the storage and loss moduli ( $G^{\prime}$ and $G^{\prime \prime}$ ) are independent of the magnitude of the applied stress. Frequency sweep measurements were performed within the linear viscoelastic region, in the range of $0.1-$ $40 \mathrm{rad} / \mathrm{s}$.

\subsubsection{Serum viscosity}

The viscosity of the serum obtained by centrifugation was measured using double gap cylinder geometry with an internal gap of $0.422 \mathrm{~mm}$, an external gap of $0.473 \mathrm{~mm}$ and $40 \mathrm{~mm}$ height. Shear rate was increased from 10 to $1000 \mathrm{~s}^{-1}$ for $4 \mathrm{~min}$ and decreased from 1000 to $10 \mathrm{~s}^{-1}$ for $4 \mathrm{~min}$; viscosity of the serum was obtained in the Newtonian plateau at low shear rate.

\section{Results and discussion}

\subsection{Effect of grinding on structural properties}

NP presented a bimodal particle size distribution, with a first peak observed at approximately $1000 \mu \mathrm{m}$ and a second one at $200 \mu \mathrm{m}$ (Fig. 1c). These two major populations of particles were identified and visualised using the confocal microscopy. Thus the larger particles represented clusters of undissociated parenchyma cells while the smallest particles were the ghosts of individual cells of the parenchyma (Fig. 1b). Evidently by grinding, the particle size distribution changed. In the case of MG purees, the peak at $1000 \mu \mathrm{m}$ that represented the cell clusters decreased and the peak at $200 \mu \mathrm{m}$ increased slightly. In HG puree, the peak at $1000 \mu \mathrm{m}$ disappeared completely, giving rise to an almost monomodal size distibution centred at $200 \mu \mathrm{m}$, indicating that the cell clusters have all been separated into individual cells by the mechanical treatment, as represented schematically in Fig. 2. Images taken by (a)

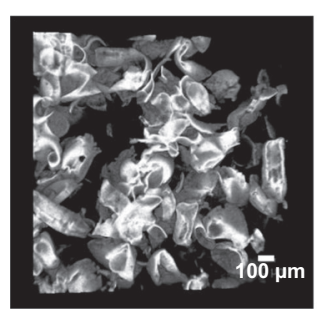

(b)
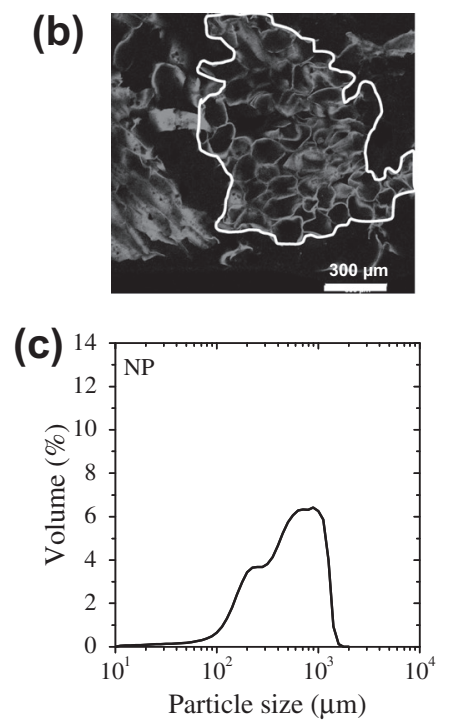
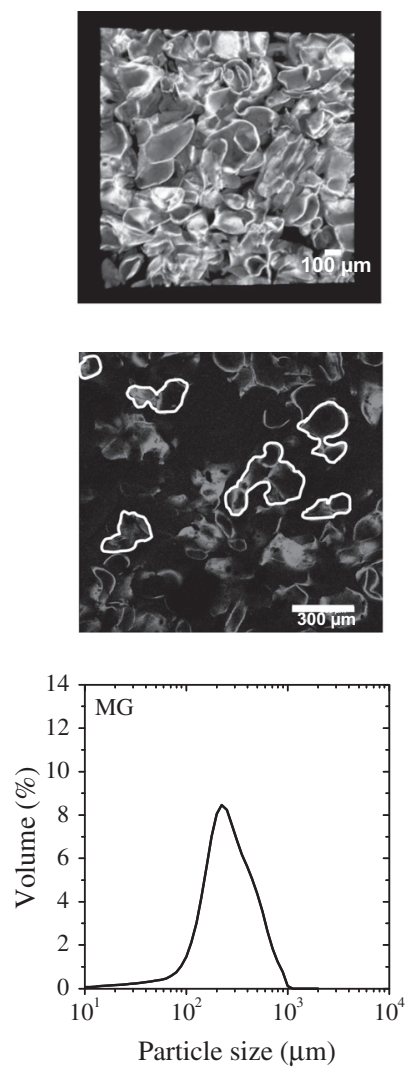
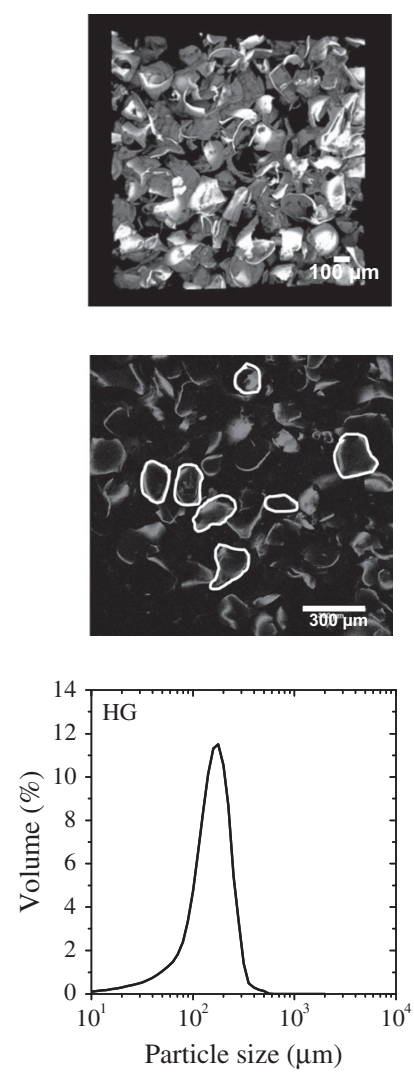

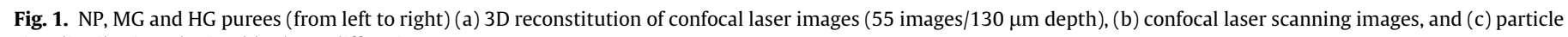
size distribution obtained by laser diffraction. 


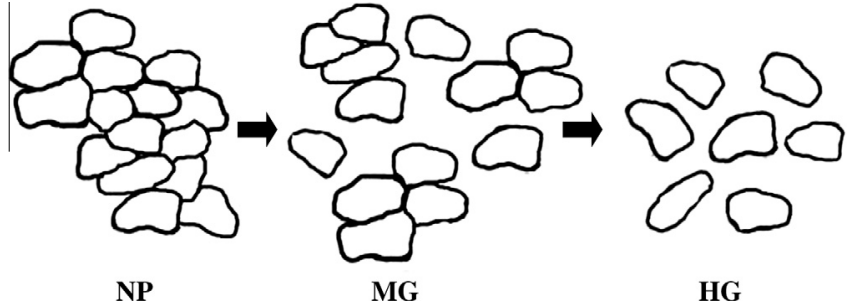

Fig. 2. Effect of grinding: schematic representation of cell wall clusters separation into individual cells.

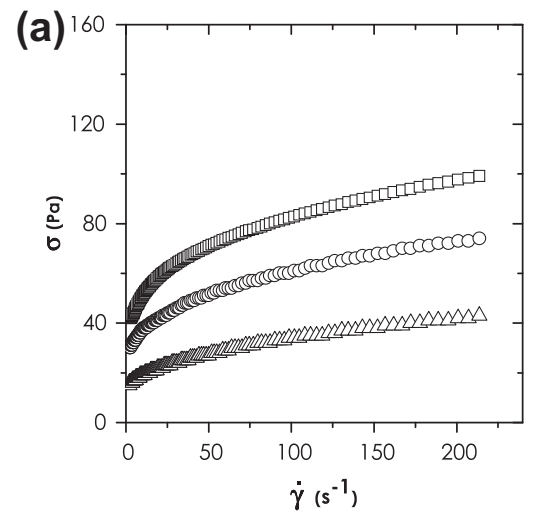

Fig. 3. (a) Flow curves of NP $(\square)$, MG $(\bigcirc)$ and $H G(\triangle)$ purees.

confocal microscopy (Fig. 1a and b) confirmed the separation of parenchyma cell clusters into single cells while grinding. The separation under mechanical shearing treatment is localised at the middle lamella weakened by the heat treatment of the NP. Microscopy also provides additional information on the morphology and the arrangement of particles in apple puree: the largest particles made up of undissociated parenchyma cells presented more irregular forms than the isolated cells.

The viscosity of the serum varied between 15 and $17 \mathrm{mPa}$ s, and was not significantly influenced by grinding (see Section 3.5 and Fig. 9).
After grinding, the cell wall content (dry insoluble solids) of apple purees did not change, and the three purees NP, MG and HG presented $11 \mathrm{~g}$ dry insoluble solids/kg. As mentioned earlier, the cell clusters were simply separated. However, with the grinding there was a slight decrease in the volume occupied by the particles after centrifugation, i.e. the pulp content; NP had a pulp content of $31 \% \mathrm{w} / \mathrm{w}, \mathrm{MG}$ of $28 \% \mathrm{w} / \mathrm{w}$ and $\mathrm{HG}$ of $27 \% \mathrm{w} / \mathrm{w}$. This decrease reflected an effect of the particle size and morphology during centrifugation as sedimentation was facilitated for the smaller and more regular particles which further could pack more densely.

\subsection{Effect of structure on steady rheological properties}

The structural parameters that were modified on apple purees to study their impact on the rheological properties were the particle size, cell wall content (dry insoluble solids) and the viscosity of the continuous phase (serum). Fig. 3 shows the flow curves (shear stress vs. shear rate) of NP, MG and HG purees. All of the purees presented a shear thinning behaviour, a yield stress and they were not time dependant (non-thixotropy), which is consistent with earlier studies on apple puree (Rao, 1986; Schijvens et al., 1998) and other fruit purees (Alvarez et al., 2008; Bhattacharya, 1999; Maceiras et al., 2007). Herschel Bulkley model was applied to estimate the yield stress. According to the structural characteristics, these rheological parameters are more or less pronounced.

The apparent viscosity $\left(43 \mathrm{~s}^{-1}\right)$ and yield stress of purees increased with the increase of insoluble solids and decreased with decreasing particle size (Table 2). Schijvens et al. (1998) observed that the apparent viscosity $\left(9.6 \mathrm{~s}^{-1}\right)$ of apple purees shows a power law dependency on the concentration of insoluble solids, which is the same trend we observed (Fig. 4) for the three levels of particle sizes. Fig. 4 reports the apparent viscosity $\left(43 \mathrm{~s}^{-1}\right)$ as a function of the dry insoluble solids concentration for the three types of particle size (NP, MG and HG). Apparent viscosity increased with a power law dependence (slope $>1$ ) with the increase of insoluble solids and it decreased as particle size decreased. In fact there is no significant interaction between concentration and particle size as observed by the parallel slopes.

By grinding, apparent viscosity $\left(43 \mathrm{~s}^{-1}\right)$ and the yield stress decreased as well as the shear thinning behaviour ( $n$ increased). Larger and irregular particles contribute to a high viscosity, thereby

Table 2

Structural and rheological and structural parameters of NP, MG, HG and reconstituted apple purees.

\begin{tabular}{|c|c|c|c|c|c|c|c|c|c|c|c|c|}
\hline \multirow[t]{2}{*}{ Sample } & \multirow{2}{*}{$\begin{array}{l}\text { Dry } \\
\text { insoluble } \\
\text { solids } \\
\text { content (g/ } \\
\text { kg) }\end{array}$} & \multirow{2}{*}{$\begin{array}{l}\text { Pulp } \\
\text { content } \\
\text { (g/100 } g \\
\text { of puree) }\end{array}$} & \multirow{2}{*}{$\begin{array}{l}d(0.9) \\
(\mu \mathrm{m})\end{array}$} & \multirow{2}{*}{$\begin{array}{l}\text { Apparent } \\
\text { viscosity } \\
43 \mathrm{~s}^{-1} \\
(\mathrm{mPa} \mathrm{s})\end{array}$} & \multirow{2}{*}{$\begin{array}{l}\text { Serum } \\
\text { viscosity } \\
\text { (mPa s) }\end{array}$} & \multirow[t]{2}{*}{$G^{\prime}(\mathrm{Pa})$} & \multirow[t]{2}{*}{$G^{\prime \prime}(\mathrm{Pa})$} & \multirow[t]{2}{*}{$\tan \delta$} & \multirow{2}{*}{$\begin{array}{l}\text { Yield } \\
\text { stress } \\
(\mathrm{Pa})\end{array}$} & \multicolumn{3}{|c|}{ Herschel Bulkley parameters } \\
\hline & & & & & & & & & & $\begin{array}{l}\text { Yield } \\
\text { stress H- } \\
\mathrm{B}(\mathrm{Pa})\end{array}$ & $n$ & $k\left(\operatorname{Pa~s}^{n}\right)$ \\
\hline NP25 & $8 \pm 1$ & $29.8 \pm 1.9$ & $1066 \pm 22$ & $1090 \pm 21$ & $17.2 \pm 0$ & $438 \pm 51$ & $119 \pm 12$ & $0.27 \pm 0.01$ & $24 \pm 3$ & $12.2 \pm 0.6$ & $0.36 \pm 0$ & $8.9 \pm 0.3$ \\
\hline NP & $11 \pm 1$ & $30.5 \pm 0.7$ & $1010 \pm 14$ & $1606 \pm 56$ & $17.2 \pm 0.5$ & $805 \pm 9$ & $189 \pm 2$ & $0.23 \pm 0$ & $43 \pm 2$ & $23 \pm 1.6$ & $0.33 \pm 0$ & $13.3 \pm 0.6$ \\
\hline NP42 & $16 \pm 1$ & $36.3 \pm 1.7$ & $1001 \pm 23$ & $2653 \pm 14$ & $16.5 \pm 0$ & $2361 \pm 73$ & $542 \pm 13$ & $0.23 \pm 0$ & $123 \pm 5$ & $43.3 \pm 2.5$ & $0.31 \pm 0.02$ & $21.1 \pm 2.3$ \\
\hline NP60 & $21 \pm 3$ & $44.3 \pm 1.2$ & $1257 \pm 153$ & $3361 \pm 78$ & $16.3 \pm 0.2$ & $3862 \pm 367$ & $895 \pm 52$ & $0.23 \pm 0.01$ & $201 \pm 13$ & $46.7 \pm 1.5$ & $0.32 \pm 0.01$ & $28.3 \pm 1.7$ \\
\hline MG22 & $7 \pm 2$ & $26.8 \pm 0.7$ & $509 \pm 12$ & $664 \pm 15$ & $14.7 \pm 0.1$ & $230 \pm 23$ & $56 \pm 4$ & $0.25 \pm 0.03$ & $8 \pm 1$ & $8.7 \pm 0.8$ & $0.44 \pm 0.01$ & $3.7 \pm 0.2$ \\
\hline MG & $11 \pm 2$ & $28.7 \pm 1$ & $500 \pm 4$ & $1177 \pm 21$ & $14.9 \pm 0.3$ & $582 \pm 35$ & $123 \pm 4$ & $0.21 \pm 0.01$ & $25 \pm 1$ & $20.4 \pm 0.2$ & $0.39 \pm 0.02$ & $6.8 \pm 0.8$ \\
\hline MG39 & $18 \pm 1$ & $36.9 \pm 1.2$ & $505 \pm 7$ & $2359 \pm 64$ & $16.6 \pm 0.1$ & $1899 \pm 147$ & $426 \pm 15$ & $0.22 \pm 0.01$ & $86 \pm 1$ & $41 \pm 2.4$ & $0.3 \pm 0.03$ & $19.2 \pm 4.1$ \\
\hline MG57 & $20 \pm 2$ & $40.9 \pm 0.4$ & $503 \pm 4$ & $2815 \pm 10$ & $17.7 \pm 0.3$ & $2471 \pm 175$ & $566 \pm 40$ & $0.23 \pm 0.01$ & $117 \pm 9$ & $42.5 \pm 0.5$ & $0.27 \pm 0.01$ & $27.6 \pm 0.8$ \\
\hline $\mathrm{HG}$ & $11 \pm 0$ & $27.8 \pm 0.2$ & $232 \pm 3$ & $622 \pm 9$ & $16.8 \pm 0.1$ & $268 \pm 15$ & $64 \pm 5$ & $0.24 \pm 0.01$ & $11 \pm 0$ & $12 \pm 0.3$ & $0.48 \pm 0$ & $2.3 \pm 0$ \\
\hline HG38 & $16 \pm 3$ & $37 \pm 1.7$ & $233 \pm 1$ & $1346 \pm 22$ & $17.5 \pm 0.1$ & $1089 \pm 31$ & $254 \pm 9$ & $0.23 \pm 0$ & $43 \pm 2$ & $25.7 \pm 1.2$ & $0.29 \pm 0.01$ & $10.7 \pm 0.9$ \\
\hline HG56 & $24 \pm 0$ & $50.5 \pm 1.3$ & $236 \pm 1$ & $2168 \pm 41$ & $18.7 \pm 0.1$ & $2587 \pm 236$ & $625 \pm 36$ & $0.24 \pm 0.01$ & $105 \pm 4$ & $38.7 \pm 1.2$ & $0.38 \pm 0.01$ & $12.2 \pm 1.6$ \\
\hline $\mathrm{NP} 25+\mathrm{P}$ & $8 \pm 1$ & $30.1 \pm 1.2$ & $939 \pm 20$ & $1386 \pm 35$ & $85.8 \pm 3.4$ & $419 \pm 18$ & $130 \pm 5$ & $0.31 \pm 0.01$ & $16 \pm 0$ & $8 \pm 0.6$ & $0.38 \pm 0$ & $13 \pm 0.1$ \\
\hline $\mathrm{NP} 42+\mathrm{P}$ & $16 \pm 1$ & $43.9 \pm 0.3$ & $895 \pm 14$ & $3051 \pm 28$ & $102.2 \pm 1.2$ & $2020 \pm 129$ & $541 \pm 16$ & $0.27 \pm 0.01$ & $93 \pm 3$ & $31 \pm 0.5$ & $0.26 \pm 0$ & $38 \pm 0.6$ \\
\hline $\mathrm{HG}+\mathrm{P}$ & $11 \pm 0$ & $38.3 \pm 1.1$ & $230 \pm 1$ & $1108 \pm 31$ & $90.1 \pm 0.9$ & $337 \pm 20$ & $114 \pm 2$ & $0.34 \pm 0.02$ & $13 \pm 1$ & $9 \pm 0.2$ & $0.42 \pm 0$ & $8 \pm 0.2$ \\
\hline $\mathrm{HG} 38+\mathrm{P}$ & $16 \pm 2$ & $46.1 \pm 0.7$ & $231 \pm 1$ & $1600 \pm 30$ & $111.7 \pm 1.2$ & $967 \pm 14$ & $299 \pm 12$ & $0.31 \pm 0.02$ & $32 \pm 1$ & $18 \pm 0.1$ & $0.37 \pm 0$ & $12 \pm 0.4$ \\
\hline
\end{tabular}


Version définitive du manuscrit publiée dans / Final version of the manuscript published in :

Journal of Food Engineering (2013), Vol. 119, №.3, p. 619-626, DOI: 10.1016/j.jfoodeng.2013.06.014

Journal homepage: http://www.elsevier.com/locate/jfoodeng

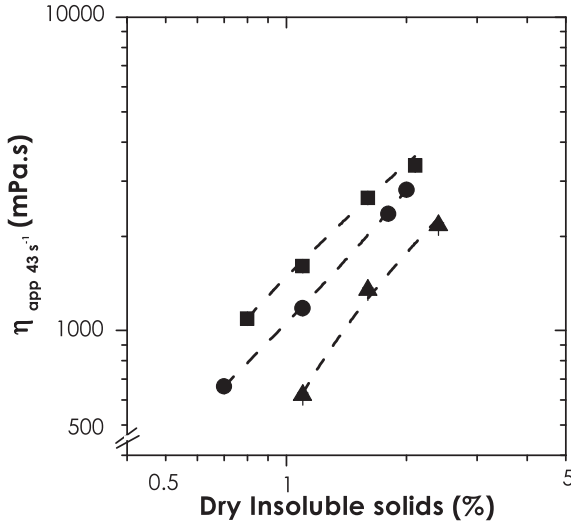

Fig. 4. Apparent viscosity as a function of dry insoluble solids for NP ( $\mathbf{\square})$, MG ( and HG $(\boldsymbol{\Lambda})$ purees.

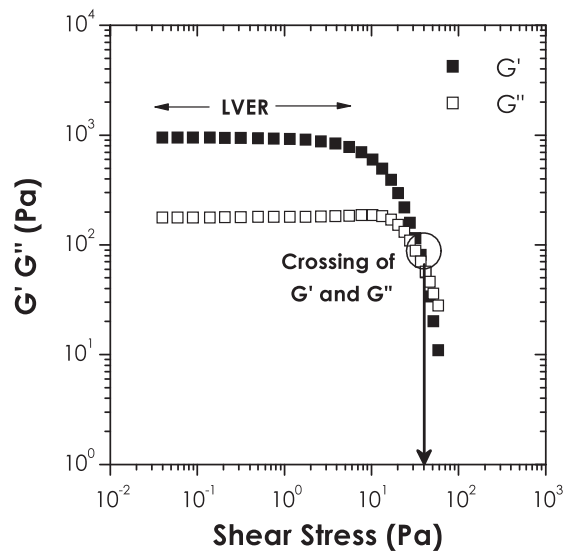

Fig. 5. Determination of the linear viscoelastic region (LVER) and the yield stress as the crossing point of $\mathrm{G}^{\prime}$ and $\mathrm{G}^{\prime \prime}$ in the oscillatory strain sweep at $10 \mathrm{rad} / \mathrm{s}$.

causing a higher hindrance to the flow than the finer and regular particles. Everything happens as if the larger particles (not separated and more irregular) occupy apparently a higher volume than individual cells.

\subsection{Effect of structure on rheological viscoelastic properties}

The yield stress value was determined from the oscillatory strain sweep tests at an angular frequency of $10 \mathrm{rad} / \mathrm{s}$. Then $G^{\prime}$ and $G^{\prime \prime}$ were plotted as a function of the shear stress as presented in Fig. 5 (example of NP) and yield stress value was determined at the crossing point of $G^{\prime}$ and $G^{\prime \prime}$. NP presented a yield stress of $43 \mathrm{~Pa}$, this value was estimated to correspond to the moment when the puree starts to flow at the macroscopic level. The values obtained by this direct method are generally higher than those obtained by extrapolation using Herschel Bulkey model (Section 3.2), see Table 2.

Fig. 6 reports the storage modulus $\left(G^{\prime}\right)$ and the loss modulus $\left(G^{\prime \prime}\right)$ as a function of the frequency. All products presented a predominantly elastic behaviour with $G^{\prime}>G^{\prime \prime}$ regardless of the frequency, this behaviour is typical of concentrated structured suspensions. It corresponds well to viscoplastic fluids presenting a yield stress. This behaviour was similar to that found in the case of other fruit and vegetable purees (Massa et al., 2010; Sato and Cunha, 2009; Valencia et al., 2002). According to the particle content or size, $G^{\prime}$ and $G^{\prime \prime}$ are more or less pronounced: NP $>M G>H G$

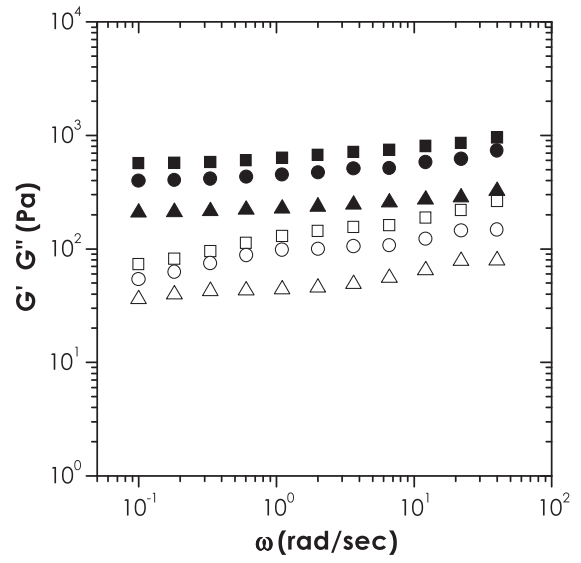

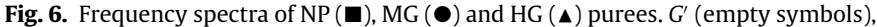
$G^{\prime \prime}$ (full symbols).

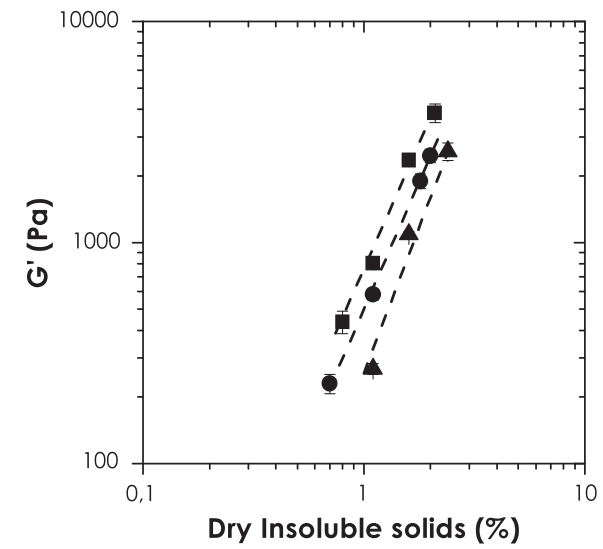

Fig. 7. Elastic modulus $G^{\prime}$ as a function of dry insoluble solids for NP (ם), MG ( and HG ( $\mathbf{\Lambda})$ purees.

as observed by Day et al., 2010 for carrot cluster and single-cells dispersions of broccoli and carrot.

Viscoelastic properties were considerably influenced by the solids content; an increase in the cell wall content led to an increase in the elastic and loss moduli. For example, the increase in dry insoluble solids content from NP $(11 \mathrm{~g} / \mathrm{kg})$ to $\mathrm{N} 21(21 \mathrm{~g} / \mathrm{kg})$ caused an increase in $G^{\prime}$ from 805 to $3860 \mathrm{~Pa}$ (Table 2). Fig. 7 illustrates the effect of dry insoluble solids content on the elastic modulus; the fact that the three slopes (NP, MG and HG) are parallel shows that there is no interaction between concentration and particle size. Moreover, the viscoelastic properties decreased with decreasing particle size; the value of $G^{\prime}$ decreasing from $805 \mathrm{~Pa}$ (NP) to $268 \mathrm{~Pa}$ (HG). The variation of the elastic modulus with the solids content shows also a power law dependence, but less marked than the flow properties (slope $\sim 2$ ) as observed in Fig. 7. Hemar et al. (2011) also observed an increase of $G^{\prime}$ with the increase of solids content. The effect of the solids content on the rheological properties will be linked to the occupancy of the volume. The place that the particles occupy at rest depends first on the concentration and at second order on the size and morphology of particles which are affected simultaneously by the grinding. Day et al., 2010 evaluated the complex modulus and observed an increase of $G^{*}$ with the increase of weight concentration and above a critical concentration the increase tended to plateau at very high concentrations. Below this critical concentration a power law equation, generally used to model the elastic behaviour of particulate networks was applied, taking into account the interaction between particles and their shapes. 
Version définitive du manuscrit publiée dans / Final version of the manuscript published in :

Journal of Food Engineering (2013), Vol. 119, №.3, p. 619-626, DOI: 10.1016/j.jfoodeng.2013.06.014

Journal homepage: http://www.elsevier.com/locate/ịfoodeng

A comparative parameter which incorporates both the elastic and viscous contributions is the phase angle $\operatorname{tangent}(\tan \delta)$, for our samples this value was considered at $12 \mathrm{rad} / \mathrm{s}$ (Table 2 ). Grinding, diluting and concentrating purees did not change the values of $\tan \delta$ varying between 0.21 and 0.24 which reflects the dominant elastic nature of purees despite their structural parameters in this studied domain.

\subsection{Effect of particle size and solids content on rheological properties:} Master curves

Rheological properties of apple purees appeared to be determined by the cell wall content, the particle size and morphology. These three parameters can be summarised by the volume fraction $\Phi$ which describes the volume effectively occupied by the particles. Even if the effective volume fraction, morphology and deformability of the particles are not directly accessible, we proposed to estimate the variation of an apparent relative volume fraction, taking as a reference the rheological properties of HG puree.

To take into account the effect of concentration and particle size and morphology, rheological master curves were established.

The base model establishes a relationship between the volume fraction $\Phi$ and rheological properties:

Rheological parameter $=A \Phi^{B}$

The volume fraction can be defined as:

$\Phi=C \cdot V$

where $V$ is the apparent voluminosity (vol/wt).

As HG puree comprises essentially individual cells and presents an homogenous particle size distribution centred at $200 \mu \mathrm{m}$, we took HG puree as the reference with an apparent voluminosity: $V_{\mathrm{HG}}$. We then introduced a factor $\alpha$ related to the particle size and morphology that can be defined as the ratio $V / V_{\mathrm{HG}}$.

The $\alpha$ factor is actually a shift factor that makes it possible to obtain a master curve, taking as reference HG puree with $V_{\mathrm{HG}}=1$.

So the values of the factor $\alpha$ for NP and MG were estimated from curves (rheological parameters plotted against concentration) and the shift factor $\alpha$ was determined so as to obtain the best fit.

Modelling was performed for three rheological parameters: the apparent viscosity $\left(43 \mathrm{~s}^{-1}\right.$ ), yield stress (crossing of $G^{\prime}$ and $G^{\prime \prime}$ ) and loss modulus $\left(G^{\prime}\right)$ :

Rheological parameter $=A(C \cdot \alpha)^{B}$

Fig. 8 presents the master curves for the three rheological parameters (apparent viscosity, yield stress and elastic modulus). A rather good fit is obtained (Fig. 8) $R^{2}>0.95$. Parameters $A$ and

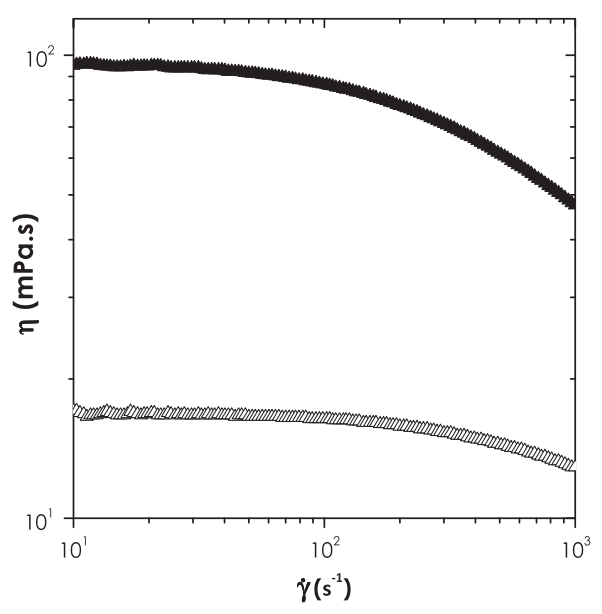

Fig. 9. HG serum viscosity $(\triangle)$ with a Newtonian behaviour and HG + Pectin added (ム) showing both Newtonian and shear thinning behaviours.

Table 3

Values of slip factors and the parameters $A$ and $B$ (please refer to Eq. (3)) obtained for each particle size (NP, MG and $\mathrm{HG}$ ).

\begin{tabular}{llllcll}
\hline Rheological parameter & $\alpha_{\mathrm{HG}}$ & $\alpha_{\mathrm{MG}}$ & $\alpha_{\mathrm{NP}}$ & \multicolumn{1}{l}{$A$} & $B$ & $R^{2}$ \\
\hline$G^{\prime}$ & 1 & 1.2 & 1.5 & 353 & 2.09 & 0.96 \\
$\sigma_{s}$ & 1 & 1.2 & 1.5 & 13.2 & 2.36 & 0.99 \\
$\eta_{\text {app 43s-1 }}$ & 1 & 1.5 & 1.8 & 649 & 1.28 & 0.98 \\
$\eta_{\text {app 10s-1 }}$ & 1 & 1.5 & 1.8 & 1953 & 1.32 & 0.96 \\
$\eta_{\text {app 200s-1 }}$ & 1 & 1.5 & 1.8 & 224 & 1.11 & 0.97 \\
\hline
\end{tabular}

$B$ (from Eq. (3)) were determined from the master curves. Their values and those of $\alpha$ (relative apparent voluminosity factor) obtained for each particle size are presented in Table 3.

The more anisotropic and larger the particles are the more effective volume they occupy. The cell clusters (found in NP) occupy a greater apparent volume than the individual cells (HG) due to their size and morphology. It can be observed that $\alpha_{\mathrm{HG}}=1<\alpha_{\mathrm{MG}}$ $<\alpha_{\mathrm{NP}}$.

This explained that for flow properties, the larger the particles were, the higher the hindrance to the flow. For $G^{\prime}$, the relative factor $\alpha$ gives an idea of the relative apparent volume occupied by the particles at rest, and the particles of NP $\left(\alpha_{\mathrm{NP}}=1.5\right)$ occupied more space than those in MG $\left(\alpha_{\mathrm{MG}}=1.2\right)$ and $\mathrm{HG}\left(\alpha_{\mathrm{HG}}=1\right)$.

Exponent $B$, reflects the dependence of the rheological properties to the concentration of the suspensions. It is slightly greater than 1 for the flow properties ( $\left.\eta_{\text {app }}\right)$, as previously shown in Section 3.2 apparent viscosity increases approximately linearly with the
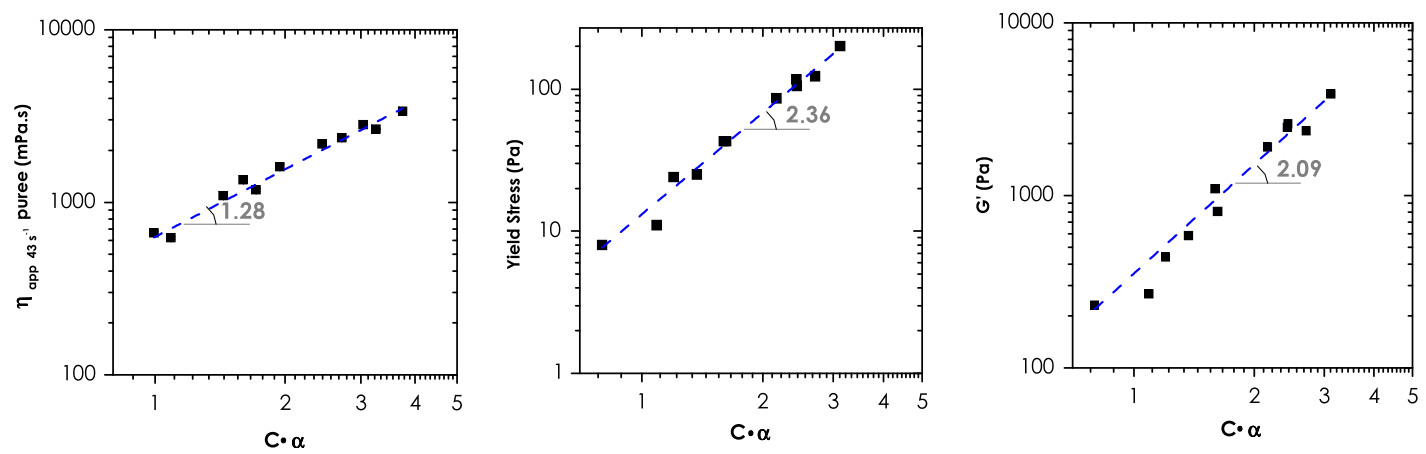

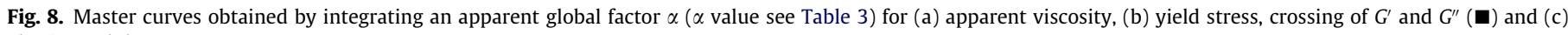
elastic modulus. 
increase of insoluble solids. $B$ is greater than 2 for the "static" properties $\left(G^{\prime}\right.$ and $\sigma_{s}$ ), thus the concentration effect did not depend significantly on the size of the particles.

As apple purees present a shear thinning behaviour (the apparent viscosity decreases when the shear rate increases), three master curves were determined at different shear rates: 10, 43 and $200 \mathrm{~s}^{-1}$. It can be observed in Table 3 that the relative $\alpha$ factor is the same for the three shear rates compared, meaning that the apparent voluminosity and thus the effect of the size and morphology are the same and do not depend on the shear rate.

\subsection{Impact of thickening the continuous phase with pectin}

With the addition of pectin, the viscosity of the serum increased (from $17 \mathrm{mPa}$ s to $90-\mathrm{mPa}$ s at low shear rate) it was multiplied by 5 as shown in Fig. 9. Non-thickened purees presented a serum with a marked Newtonian plateau as observed in carrot, broccoli and tomato purees (Lopez-Sanchez et al., 2011). It can be seen in Fig. 9 that with the addition of pectin this Newtonian plateau became smaller and a shear thinning behaviour appeared as the shear rate increases, which can be attributed to the entanglements of pectin chains present in the serum.

Changing the viscosity of the continuous phase makes it possible to modify the global consistency of the puree in a different way than by changing the cell wall content. The addition of pectin and thus the thickening of the serum causes an increase in the apparent viscosity but a decrease in the yield stress. If we assume that the yield stress is the expression of cohesion between particles, we can suppose that the increase of the viscosity of the serum has limited this cohesion between particles. With the addition of pectin, the elastic character decreased slightly but significantly and $\tan \delta$ increased from 0.27 to 0.34 . Pectin might play a lubricating role, limiting the cohesion between particles. This "lubricant effect" was also observed in texture perception of apple purees with the addition of pectin and therefore a higher viscosity of the serum, the products are perceived as more consistent and less grainy than the similar purees without pectin (Espinosa-Muñoz et al., 2012). The lubricating role of pectin will influence the perception of "graininess" giving a "smoother" perception.

These structural parameters are important in the formulation of new products, especially their texture. An example is that by increasing the viscosity of the serum of a highly ground puree from 17 to $90 \mathrm{mPa}$ s, the puree can reach the viscosity level of a medium ground (MG) puree (1177 mPa s), but with a lower yield stress and a higher value of $\tan \delta$, presenting a less elastic behaviour. In sensory terms, the perceived consistency of a HG-P is the same as the MG but the graininess perceived is lower in HG-P than MG (Espinosa-Muñoz et al., 2012).

\section{Conclusions}

The objective of this study was to evaluate the influence of the structural properties on the rheological behaviour of apple purees, taking into account the effect of mechanical treatment.

The mechanical treatment (grinding) of apple purees resulted in the separation of cell wall clusters into individualised cell ghosts; this was confirmed by microscopic observations as well as changes in the morphology and particle size distribution of the purees. These are important structural changes that have an impact on the rheological properties.

Apple purees are concentrated structured suspensions with a dominant elastic behaviour, where $G^{\prime}>G^{\prime \prime}$ regardless of the frequency. All the samples presented a shear thinning behaviour and a yield stress as previously observed for cell wall dispersions (Cepeda and Gomez, 2002; Colin-Henrion et al., 2009; Sato and
Cunha, 2009). The apparent viscosity and yield stress increased with the insoluble solids content (cell walls), the medium being more crowded. The apparent viscosity and the yield stress decreased with decreasing particle size. The viscoelastic properties of the purees thus increased with the cell wall content and with the particle size.

A third structural parameter was the viscosity of serum (continuous phase). With the addition of pectin, serum viscosity increased and thereby the global viscosity of the puree. However, the yield stress decreased, indicating an effect on the cohesion of the suspension: increasing serum viscosity caused a slight decrease on the elastic behaviour, giving rise to a lubricating effect.

The modelling of rheological properties with master curves made it possible to take into account the apparent relative volume occupied by the particles of different sizes. This could be quantified by the relative factor $\alpha$, which describes how cell ghost clusters occupy more space than the individual cell ghosts and thus they affect the rheological properties in different ways. The effect of the concentration of insoluble solids on the rheological properties was modelled by a simple power law (master curves) whose exponent was independent on the intensity of grinding.

The texture of plant food dispersions can be understood and modulated by controlling a few selected key structural parameters: the concentration of cell walls (pulp) and particle size, completed by the viscosity of the continuous phase (Espinosa-Muñoz et al., 2012). High possibilities for innovation are opened by playing on these parameters that can be modified during the processing.

Further studies will complete this approach to estimate the volume fraction of particles in apple purees.

\section{Acknowledgements}

This work was supported by the Agence Nationale de la Recherche within Project ANR-07-PNRA-030 TEMPANTIOX "New processes for production of fruit derived products with optimised organoleptic and nutritional qualities".

Authors would like to thank Gabrielle Moulin for her help in confocal microscopy.

\section{References}

Ahmed, J., Ramaswamy, H.S., 2007. Dynamic rheology and thermal transitions in meat-based strained baby foods. Journal of Food Engineering 78 (4), 12741284.

Alvarez, E., Cancela, M.A., Delgado-Bastidas, N., Maceiras, R., 2008. Rheological characterization of commercial baby fruit purees. International Journal of Food Properties 11 (2), 321-329.

Bhattacharya, S., 1999. Yield stress and time-dependent rheological properties of mango pulp. Journal of Food Science 64 (6), 1029-1033.

Cepeda, E., Gomez, R., 2002. Rheological characteristics of pimento puree: theoretical interpretation. Journal of Food Science 67 (7), 2734-2738.

Colin-Henrion, M., Mehinagic, E., Patron, C., Jourjon, F., 2009. Instrumental and sensory characterisation of industrially processed applesauces. Journal of the Science of Food and Agriculture 89 (9), 1508-1518.

Day, L., Xu, M., Oiseth, S., Lundin, L., Hemar, Y., 2010. Dynamic rheological properties of plant cell-wall particle dispersions. Colloids and Surfaces B 81, 461-467.

Den Ouden, F.W.C., Van Vliet, T., 2002. Effect of concentration on the rheology and serum separation of tomato suspensions. Journal of Texture Studies 33, 91-104.

Espinosa-Muñoz, L., Symoneaux, R., Renard, C.M.G.C., Biau, N., Cuvelier, G., 2012. The significance of structural properties for the development of innovative apple puree textures. LWT - Food Science and Technology 49, 221-228.

Hemar, Y., Lebreton, S., Xu, M., Day, L., 2011. Small-deformation rheology investigation of rehydrated cell wall particlesexanthan mixtures. Food Hydrocolloids 25, 668-676.

Khan, A.A., Vincent, J.F.V., 1993. Anisotropy in the fracture properties of apple flesh as investigated by crack-opening tests. Journal of Materials Science $28,45-51$.

Kunzek, H., Kabbert, R., Gloyna, D., 1999. Aspects of material science in food processing: changes in plant cell walls of fruits and vegetables. Zeitschrift fur Lebensmittel-Untersuchung und-Forschung A - Food Research and Technology 208, 233-250.

Kunzek, H., Opel, H., Senge, B., 1997. Rheological examination of material with cellular structure. II. Creep and oscillation measurements of apple material with 
Version définitive du manuscrit publiée dans / Final version of the manuscript published in :

Journal of Food Engineering (2013), Vol. 119, $\mathbf{N}^{\circ} .3$, p. 619-626, DOI: 10.1016/j.jfoodeng.2013.06.014

Journal homepage: http://www.elsevier.com/locate/ifoodeng

cellular structure. Zeitschrift fur Lebensmittel-Untersuchung und-Forschung A - Food Research and Technology 205 (3), 193-203.

Lopez-Sanchez, P., Nijsse, J., Blonk, H.C.G., Bialek, L., Schumm, S., Langton, M., 2011. Effect of mechanical and thermal treatments on the microstructure and rheological properties of carrot, broccoli and tomato dispersions. Journal of the Science of Food and Agriculture 91, 207-217.

Maceiras, R., Alvarez, E., Cancela, M.A., 2007. Rheological properties of fruit purees: effect of cooking. Journal of Food Engineering 80 (3), 763-769.

Massa, A., Gonzalez, C., Maestro, A., Labanda, J., Ibarz, A., 2010. Rheological characterization of peach purees. Journal of Texture Studies 41 (4), 532-548.

Nindo, C.I., Tang, J., Powers, J.R., Takhar, P.S., 2007. Rheological properties of blueberry puree for processing applications. LWT - Food Science and Technology 40 (2), 292-299.

Qiu, C.G., Rao, M.A., 1988. Role of pulp content and particle size in yield stress of apple sauce. Journal of Food Science 53 (4), 1165-1170.

Rao, M.A., 1986. Rheology of apple sauce: effect of apple cultivar, firmness, and processing parameters. Journal of Food Science 51 (1), 176-179.

Rao, M.A., 1992. Review: the structural approach to rheology of plant food dispersions. Revista Espanola de Ciencia y Tecnologia de Alimentos 32 (1), 3-17.
Rao, M.A., 1999. Rheology of Fluid Semisolid Foods. Principles and Applications, second ed. Springer, Geneva, NY.

Redgwell, R.J., Fischer, M., 2005. Dietary fiber as a versatile food component: an industrial perspective. Molecular Nutrition \& Food Research 49 (6), 521-535.

Renard, C., 2005. Variability in cell wall preparations: quantification and comparison of common methods. Carbohydrate Polymers 60 (4), 515-522.

Sato, A.C.K., Cunha, R.L., 2009. Effect of particle size on rheological properties of jaboticaba pulp. Journal of Food Engineering 91, 556-570.

Schijvens, E.P.H.M., van Vliet, T., van Dijk, C., 1998. Effect of processing conditions on the composition and rheological properties of applesauce. Journal of Texture Studies 29, 123-143.

Sun-Waterhouse, D., 2010. The development of fruit-based functional foods targeting the health and wellness market: a review. International Journal of Food Science \& Technology 46 (5), 899-920.

Valencia, C., Sánchez, M.C., Ciruelos, A., Latorre, A., Franco, J.M., Gallegos, C., 2002. Linear viscoelasticity of tomato sauce products: influence of previous tomato paste processing. European Food Research and Technology 214, 394-399.

Vitali, A.A., Rao, M.A., 1982. Flow behavior of guava puree as a function of temperature and concentration. Journal of Texture Studies 13 (3), 275-289. 